\title{
Cross sectional subcostal echocardiography: atrioventricular septal defects and the short axis cut
}

\author{
CARLOS MORTERA, MIGUEL RISSECH, MARIA PAYOLA, CASIMIRO MIRO, \\ ROSA PERICH* \\ From the Cardiologia Pediatrica, Hospital Infantil San Juan de Dios; and *Clinica Nen Jesus Sabadell, \\ Barcelona, Spain
}

SUMMARY A short axis echocardiographic cut of the heart from the subcostal approach was used to study the atrioventricular junction in 47 infants and children with congenital heart disease and 20 with normal hearts. Examination of the diastolic openings of both atrioventricular valves was able to establish normal developments of the valves and annuli even when this was found in cases of complex congenital heart disease. In 30 patients with atrioventricular septal defects the technique distinguished between a partial defect (when the two atrioventricular valves were linked transseptally) and a complete defect (when there was only one atrioventricular valve). A range of atrioventricular attachments was seen in these patients.

Short axis echocardiography from the subcostal approach reliably identifies different forms of atrioventricular septal defects by defining the anatomy of the atrioventricular valves during maximal diastolic expansion.

The echocardiographic evaluation of atrioventricular septal defects ${ }^{1}$ was initially carried out by $M$ mode echocardiography. ${ }^{2-4}$ Cross sectional echocardiography, however, gives more information and is more accurate. ${ }^{5-7}$

There has been extensive anatomical analysis of the different forms of this cardiac malformation. $^{8-10}$ This information $^{11-13}$ has led to an understanding of the echocardiographic features of the lesion, ${ }^{14}$ is but identification of the different types of atrioventricular septal defect continues to be difficult. ${ }^{16-18}$

In hearts with an atrioventricular septal defect both atrioventricular valves may be attached to the interventricular septum at the same level, forming two valves and two annuli, or there may be a single atrioventricular valve with one annulus common to both atria and both ventricles. It is possible to identify these two forms by examining the attachment of the atrioventricular valve(s) to the septum in a four chamber view. ${ }^{19}$ There are, however, intermediate

Requests for reprints to Dr Carlos Mortera, Cardiologia Pediatrica, Hospital Infantil San Juan de Dios, Carretera de Esplugas s/n, 08034 Barcelona, Spain.

Accepted for publication 19 March 1987 forms of the lesion in which the leaflets of a common atrioventricular valve are tethered to the septum. ${ }^{20}$ Sutherland $e t \mathrm{al}^{21}$ and Medina $e a^{22}$ used M mode echocardiography from the subcostal approach in an attempt to improve identification of the intermediate forms. The $M$ mode echocardiogram gave only a limited display of the cardiac anatomy that was difficult to understand.

We have used cross sectional short axis cuts of the heart at the level of the atrioventricular junction to examine more accurately the normal atrioventricular valve structures and to identify various forms of atrioventricular septal defect.

\section{ECHOCARDIOGRAPHIC ANATOMY}

The understanding of cardiac anatomy from cross sectional echocardiography is based on anatomical identification of different cardiac cuts from pathological specimens. ${ }^{1923}$ In normal hearts the cross sectional short axis view at the level of the atrioventricular valves shows two independent and well formed atrioventricular annuli with valves anchored to the left and right lateral heart walls as well as to the anteriorsuperior and posteriorinferior walls. The atrioventricular septum supports the septal leaflets of both atrioventricular valves (fig 1). The form of the atrioventricular valves and leaflets is best dis- 


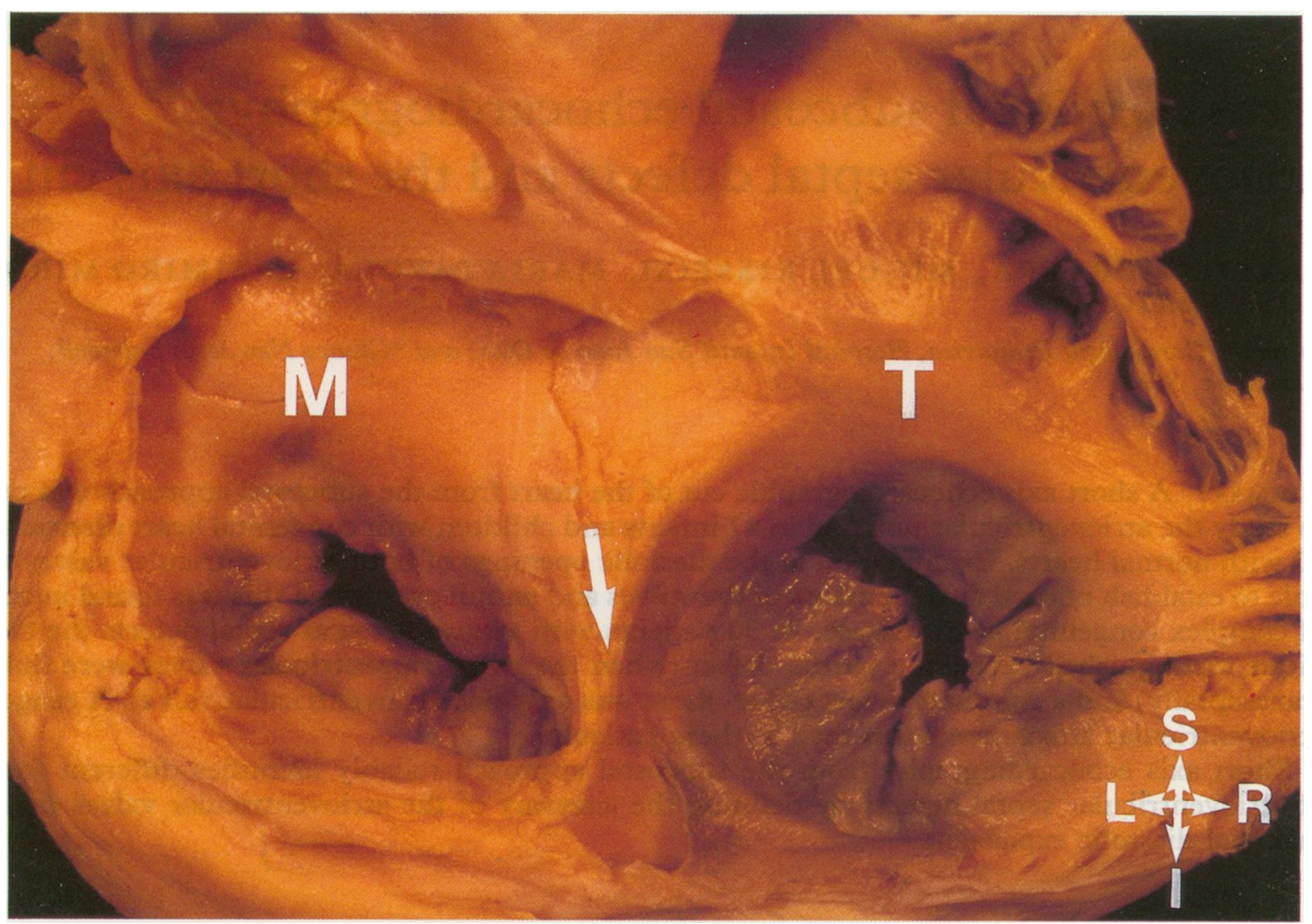

Fig 1 Normal heart cut at the level of both atrioventricular valves. The atria have been removed and the tricuspid $(T)$ and the mitral $(M)$ valves are seen from above. The arrow indicates the superior part of the atrioventricular septum that separates both atrioventricular valves. I, inferior; $L$, left; $R$, right; $S$, superior.

played during diastole, when extension of the valve components is greatest (fig 2).

In hearts with atrioventricular septal defects, either partial or complete, separate insertion of the two atrioventricular valves on to the septum is impossible. This is true of the two valves that are present in partial intraventricular septal defect or the one valve that is common to the four chambers of the heart when the defect is complete. The crest of the defective interventricular septum cannot adequately support the septal leaflets of the atrioventricular valves, and their insertion below the level of attachment of the valve leaflets in the lateral walls distorts the atrioventricular rings. In the partial form there are two atrioventricular valves and the anteriorsuperior and posterior or inferior septal components of the mitral and tricuspid valves are joined over the ventricular septum. The septal leaflets cover the crest of the interventricular septum with valve tissue to a variable degree (fig 3 ). In the complete form a single atrioventricular valve has an annulus that is common to both atria and both ven- tricles. The septal components of the common valve bridging the septum can be identified by a study of the variable number of chordal attachments and the different degrees to which the leaflets bridge the sep- $\frac{5}{3}$ tum. At its centre the crest of the septum is free of valve tissue; there is a gap between the anteriorsuperior and posteriorinferior leaflets of the common valve (fig 4). In the intermediate form the crest $\frac{}{5}$ of the interventricular septum is partially covered to $\frac{T}{0}$ a varying extent with valve tissue.

\section{Patients and methods}

Sixty seven patients aged one day to 12.5 years (mean age of 3.2 years) were studied by clinical examination, electrocardiography, chest $x$ ray, and echocardiography ( $M$ mode, cross sectional imag- o ing, and pulsed Doppler ultrasound). An atrio- -7 ventricular defect was diagnosed in 30 patients. In six this was partial, in 21 it was complete, and in three it was regarded as intermediate. In six patients anatomical confirmation of the lesion was obtained 


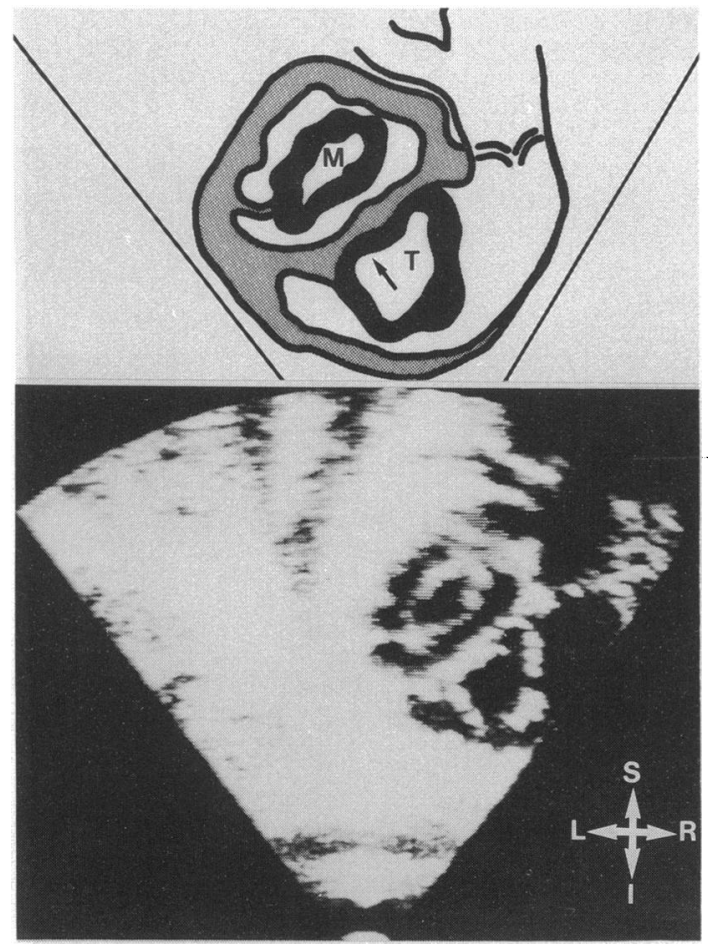

Fig 2 Echocardiogram obtained from the subcostal approach in a child with a normal heart. Transversal short axis cut shows two independent atrioventricular valves at maximum aperture during diastole. The excursion of the septal leaflet of the tricuspid valve ( $T$ ) opening is limited by the septum (arrow), whereas maximum excursion of the septal leaflet of the mitral valve $(M)$ does not take it within reach of the septum. See legend to fig 1 for abbreviations.

at cardiac catheterisation, angiography, and operation. In a further four patients diagnosis was confirmed by cardiac catheterisation only and in three by necropsy only. We also studied 20 normal children with innocent murmurs and 17 children with complex congenital heart disease. Anatomical confirmation of diagnosis in those with complex congenital heart disease was established by cardiac catheterisation in all and by necropsy in some.

For echocardiography we used a Honeywell Ultraimager machine equipped with a strip chart recorder and video system that allowed frame selection for evaluation of the anatomical data. We used 3.5 or $5 \mathrm{MHz}$ transducers according to the patient's size and the best definition. We used pulsed Doppler ultrasound to assess function. In all patients the following echocardiographic views were imaged.

(a) Parasternal approach-long axis, short axis at different levels, and apical four chamber. (b) Subcostal approach-short axis at atrial level, atrioventricular junction, and ventricular level. Subcostal short axis cuts (fig 5) were obtained by scanning from the ventricles to the atria. Valve anatomy was studied at a level at which the valve leaflets appeared to be separate from the chamber walls.

\section{Results}

Group 1-In the 20 patients with innocent murmurs who clinically and by other means had a normal heart subcostal echocardiography showed two valve orifices at the atrioventricular junction at maximal diastolic opening. These two orifices were separated by the interventricular septum. Part of the tricuspid valve lay in close apposition to the septum and during diastolic opening the orifice expanded to the right. The orifice of the mitral valve on the other hand lay well away from the septum (fig 2).

Group 2-In 17 patients echocardiographic examination confirmed complex congenital heart disease in patients who had an apparently normally developed atrioventricular junction and valve rings. The echocardiographic appearance of the atrioventricular openings was normal. This result was confirmed by cardiac catheterisation and necropsy. Group 3-In 30 patients echocardiographic examination showed an atrioventricular septal defect. Six of these patients had a partial defect-the so-called ostium primum lesion. Subcostal echocardiography showed two atrioventricular valves that were continuous with each other over the crest of the interventricular septum (fig 6). All six patients had an ostium primum septal defect. Three had an additional small ventricular septal defect outside the inlet portion of the septum. A further 21 patients had a complete atrioseptal defect. Echocardiography identified only one atrioventricular valve common to both atria and ventricles. Anteriorsuperior and posteriorinferior bridging leaflets crossed the septum and with the lateral valve leaflets formed a single valve and a common orifice (fig 7).

Valve tissue was attached to varying extents to the crest of the interventricular septum; whenever one of the septal leaflets clearly bridged the septum (fig 8) a single atrioventricular valve and annulus was present. The degree of approximation between the septum and the valve leaflets varied. With complete defects there was always a gap in the attachments of the valve tissue to the septum. In three cases the echocardiogram suggested the presence of an intermediate form (fig 8). This was confirmed in one case at operation.

After surgical correction in the complete form, the two newly created valve orifices could be identified. 


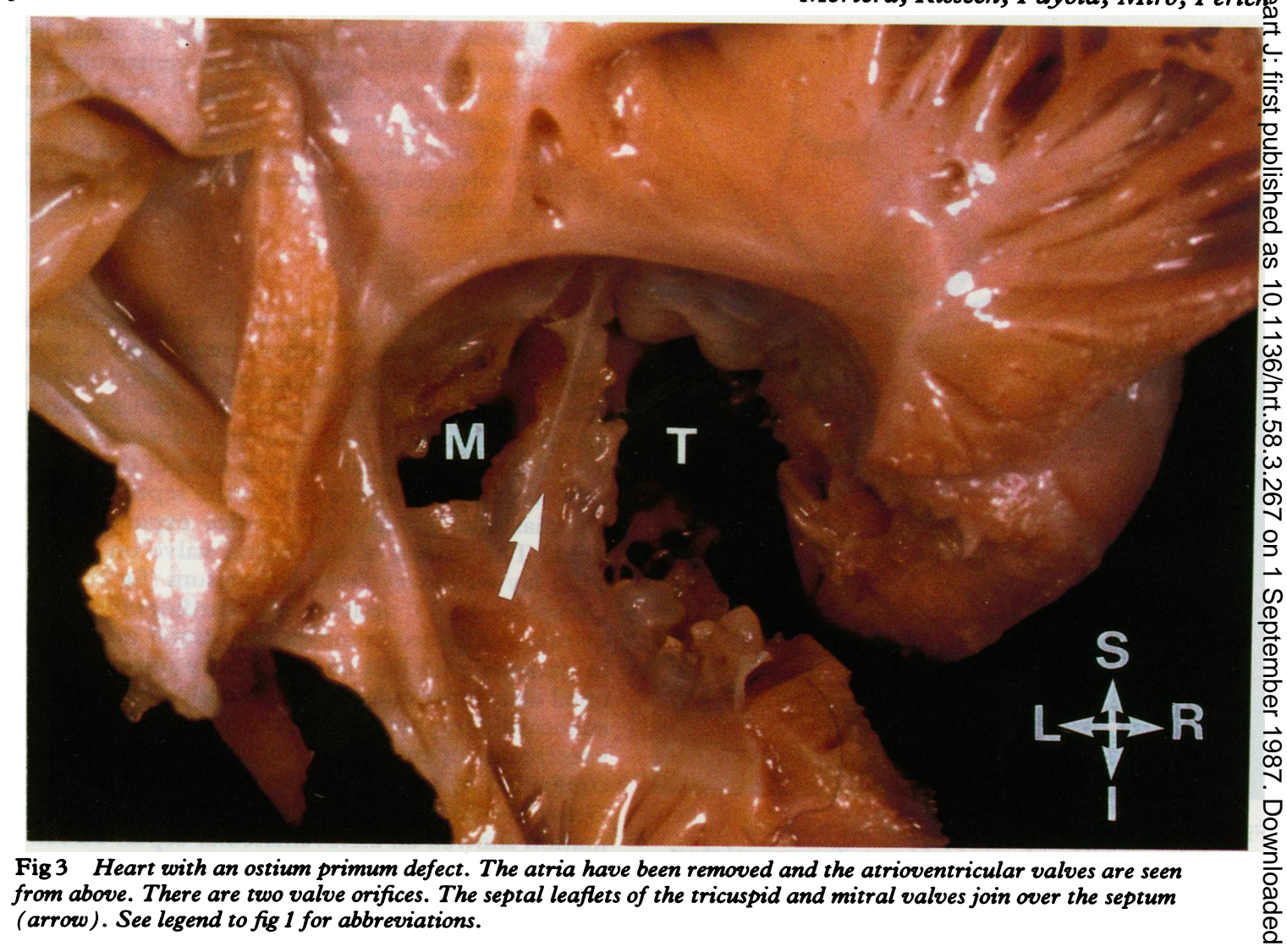
from above. There are two valve orifices. The septal leaflets of the tricuspid and mitral valves join over the septum (arrow). See legend to fig 1 for abbreviations.

In the partial form the changes were not so pronounced and were obvious only when the gap between the septal bridging leaflets at the mitral end had been repaired.

\section{Discussion}

Atrioventricular septal defects result from a maldevelopment of the atrioventricular septum and atrioventricular valves. ${ }^{911}$ Cross sectional echocardiography is the best non-invasive way to study the atrioventricular junction. ${ }^{619}$ Recent studies have demonstrated the correlation between the distorted cardiac anatomy found in these hearts and the echocardiographic images. ${ }^{14}$ Furthermore, the subcostal approach appears to be the best method of studying the atrioventricular junction. ${ }^{21} 22$ In this group of patients the short axis view from the subcostal approach was found to be the most valuable echocardiographic plane for evaluating the annuli and the atrioventricular valves.

Most of the echocardiographic studies of atrioventricular septal defects have based their anat- omical understanding of this lesion on schematic $\stackrel{\overrightarrow{3}}{3}$ diagrams of the arrangement at the level of the atrio- ventricular valve. Moreover, heart specimens veryo rarely have been cut in the short axis plane to illustrate the range and degree of valve anomaly seen in $\widetilde{0}$ atrioventricular septal defects (figs 1,3 , and 4). The? four chamber view has usually been used to evaluate this lesion.

The four chamber view from the subcostal orô parasternal approach is likely to detect the presence of a defect under the anterior or posterior bridging? leaflet that may be only apparent in systole. But the $>$ short axis view in diastole, however, will be more을. sensitive to defects in the atrioventricular valves. Another limitation of the four chamber view is its inability to visualise simultaneously the anterior ando posterior valve components.

We found that the short axis subcostal approacho clearly demonstrated the two atrioventricular valveso and normal valve anatomy even in patients with complex congenital cardiac malformation of other areas of the heart.

Our echocardiographic evaluation was performed 


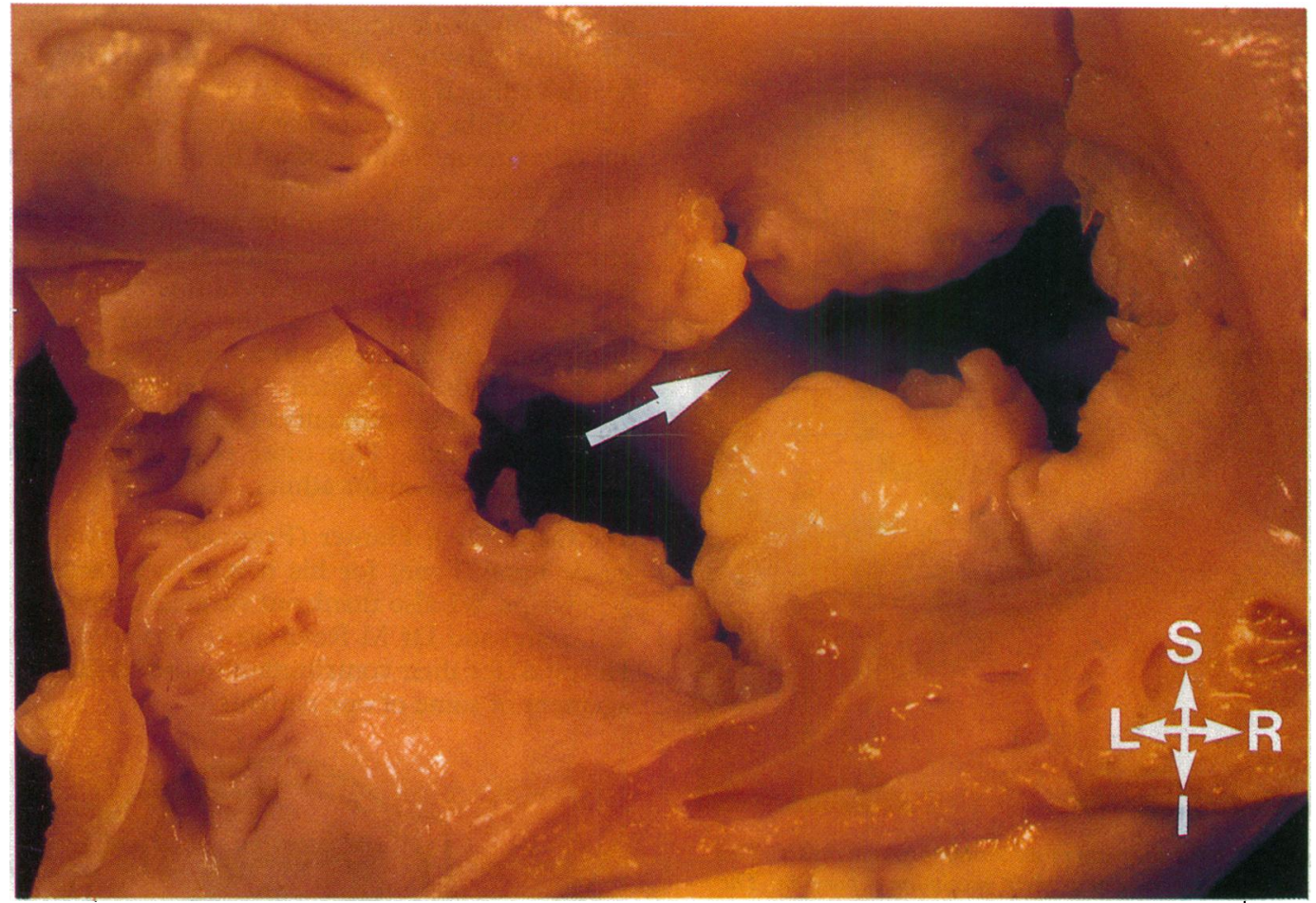

Fig 4 Heart with a complete atrioventricular septal defect. Only one valve and one annulus are seen from above. The anterosuperior and posteroinferior septal components are not fused. The crest of the interventricular septum is seen underneath. See legend to fig 1 for abbreviations.

during diastole when the valve tissue was widely separated and the two atrioventricular valve contours could be seen entirely. In normal patients two annuli were easily identified. At maximum diastolic aperture the anterior leaflet of the mitral valve was clearly separated from the septum and a well defined circle was formed. In contrast, the orifice of the tricuspid valve was limited by the interventricular septum (fig 2).

We found that valve anatomy was quite different in patients with atrioventricular septal defects. With a partial defect the two annuli were joined over the interventricular septum. Neither valve had a circular orifice; both were oval because of the attachment of the bridging leaflets to the crest of the interventricular septum (fig 6). When the defect was complete there was a large atrioventricular valve orifice that was common to both atria and both ventricles. Because there was no coaptation of the septal components in the middle of what should be the mitral and tricuspid valves a common valve orifice was formed (fig 7). The valve contours represented the septal leaflets of both valves which formed a continuous bridge over the interventricular septum. In
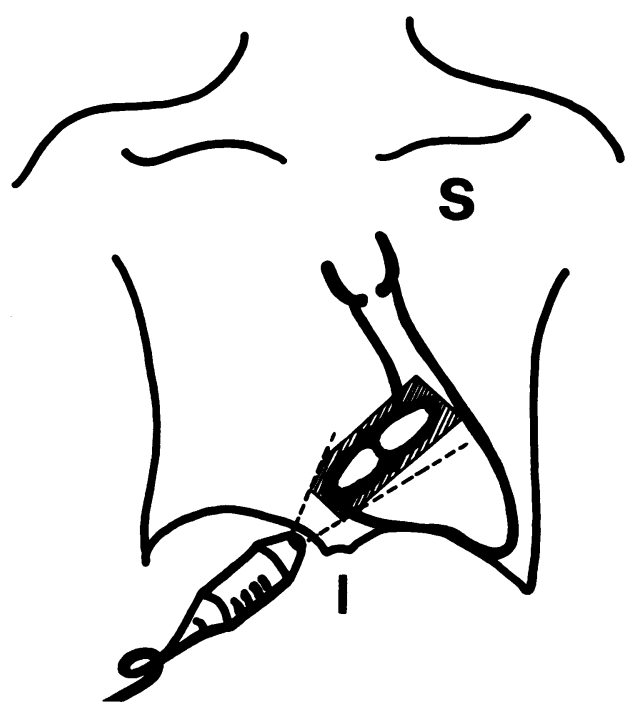

Fig 5 Diagram to show the transducer orientation from the subcostal approach. 


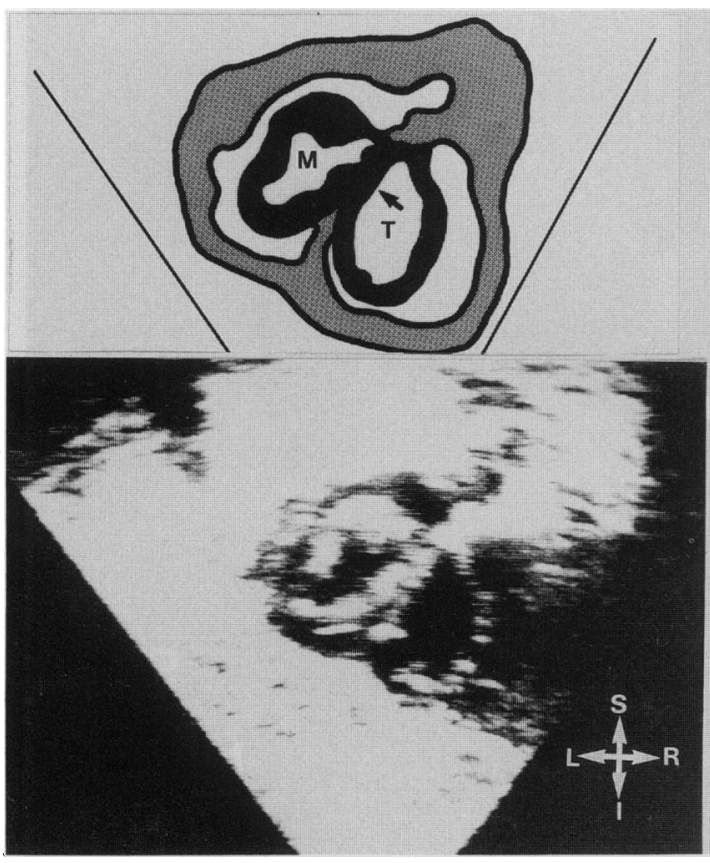

Fig 6 Echocardiogram of an ostium primum defect. Two valve orifices were seen at their maximum expansion. The septal leaflets of both valves were fused over the septum (arrow). See legend to fig 1 for abbreviations.

some cases one of the leaflets was anchored to the crest of the septum but there was a gap between the valve and septum (fig 8 ) and only one valve was present. Surgical correction created a more normal arrangement of the atrioventricular valves with the formation of two valve rings; however, the valves lay abnormally close to the septum.

We found that the short axis cut from the subcostal approach clearly displayed normal anatomy of atrioventricular valves even when this was found in cases of complex congenital heart disease. The technique discriminated between partial (two atrioventricular orifices) and complete (one orifice) atrioventricular septal defects and showed the degree of apposition between the anteriorsuperior and posteriorsuperior leaflets of the atrioventricular valve. The degree of attachment of valve tissue to the crest of the septum could also be visualised. This view was usually more helpful than the four chamber view for reliably identifying the various forms of the defect. In the intermediate form of the defect two valves are almost formed but a small degree of separation of the septal cusp tissue remains. These specimens resemble a partial form but there is a small gap in the valve tissue. When the full contours of the valves are imaged the three forms can be $\stackrel{c}{.}$ identified reliably. A short axis cut at atrial level may $\overrightarrow{\vec{F}}$ be misleading if part of the ostium primum defect is $\overrightarrow{0}$ taken to be the orifice of the valve. In this situation $\frac{c}{0}$ the valve tissue contours must be imaged before the type of defect can be identified.

The precise definition of the anatomy of the atrioventricular valve by echocardiography makes it pos- $\sigma$ sible to establish the diagnosis of this malformation $\vec{\circ}$ and allows evaluation of the degree of valve $\overrightarrow{\vec{H}}$ distortion-this is important information when sur- $\stackrel{\omega}{\omega}$ gical correction is planned. The only limitation of the approach is the difficulty of seeing the heart from 0 the subcostal axis. This route is suitable for small children but less so for adults.

We thank Dr S Hunter (Freeman Hospital, Newcastle upon Tyne) for his helpful criticism of the typescript. We also thank our surgical colleagues $\mathrm{Dr}_{\mathcal{C}}$ C Lozano and Dr M Rovirosa (R S Vall d'Hebron Hospital) for their contribution to the surgical management of some of our patients.

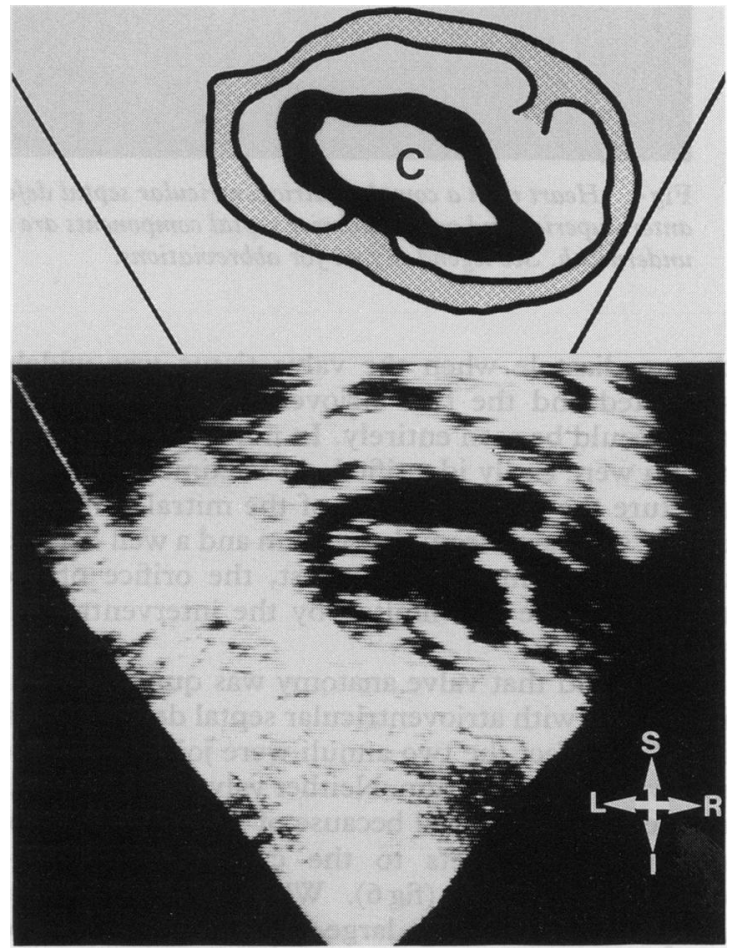

Fig 7 Echocardiogram from a patient with a complete atrioventricular defect. Only one valve was seen at diastolic maximum aperture. This was common to all four chambers. The components of the septal valves were not fused in the middle as they were in the partial form. They formed a continuous bridge over the septum and so there was one valve ring. C, common valve. See legend to fig 1 for abbreviations. 


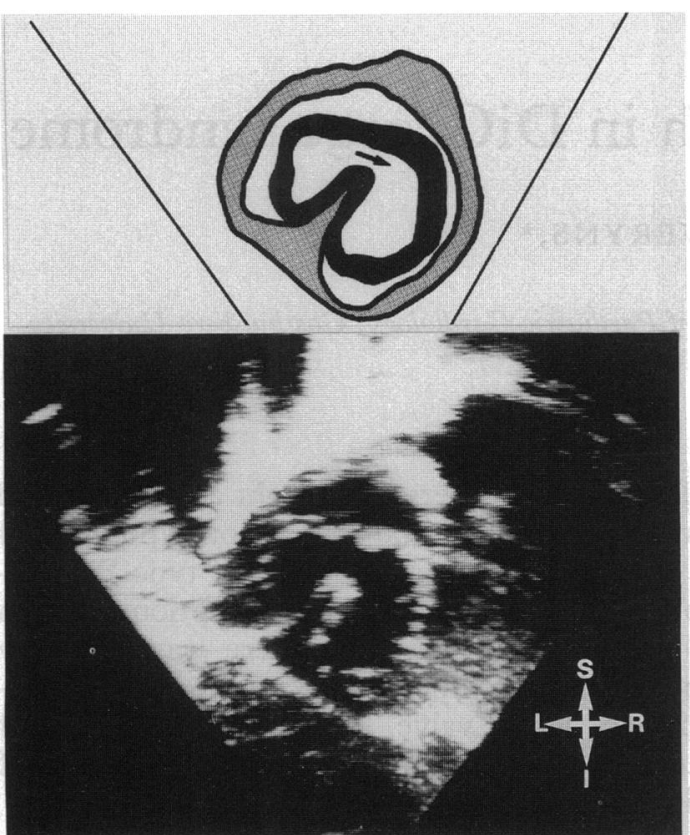

Fig 8 Echocardiogram from a patient with an intermediate form of atrioventricular septal defect. The components of the septal valves were not fused (arrow). Only the anterosuperior valve leaflet bridged the septum and was common to both ventricles and atria. The posteroinferior septal component was anchored to the crest of the septum and partly separated both valve orifices.

\section{References}

1 Williams RG, Rudd M. Echocardiographic features of endocardial cushion defects. Circulation 1974;49: 418-22.

2 Pieroni DR, Homcy E, Freedom RM. Echocardiography in atrioventricular canal defect: a clinical spectrum. Am J Cardiol 1975;35:54-8.

3 Komatsu Y, Nagai Y, Shibuya M, Takao A, Hirosawa K. Echocardiographic analysis of intracardiac anatomy in endocardial cushion defect. Am Heart J 1976;91:210-8.

4 Beppu S, Nimura Y, Nagata S, et al. Diagnosis of endocardial cushion defect with cross-sectional and $\mathbf{M}$ mode scanning echocardiography. Differentiation from secundum atrial septal defect. Br Heart $J$ 1976;38:911-20.

5 Sahn DJ, Terry RW, O'Rourke R, Leopold G, Friedman WF. Multiple crystal echocardiographic evaluation of endocardial cushion defect. Circulation 1974;50:25-32.

6 Hagler DJ, Tajik AJ, Seward JB, Mair DD, Ritter DG. Real-time wide angle sector echocardiography: atrioventricular canal defects. Circulation 1979;59: 140-50.

7 Seward B, Tajik AJ, Hagler DJ. Two-dimensional echocardiographic features of atrioventricular canal defect. In: Lundström NR, ed. Pediatric echocardiography-cross-sectional, M-mode, and Doppler. Amsterdam: Elsevier/North Holand, 1980:197-206.

8 Campbell M, Missen GAK. Endocardial cushion defects: common atrio-ventricular canal and ostium primum. Br Heart J 1957;19:403-18.

9 Rastelli G, Kirklin JW, Titus JL. Anatomic observations on complete form of persistent common atrioventricular canal with special reference to atrioventricular valves. Mayo Clin Proc 1966;41:296-308.

10 Bharati S, Lev $M$. The spectrum of common atrioventricular orifice (canal). Am Heart J 1973;83: 553-61.

11 Ugarte M, Enriquez de Salamanca F, Quero M. Endocardial cushion defects. An anatomical study of 54 specimens. Br Heart $J$ 1976;38:674-82.

12 Piccoli GP, Gerlis LM, Wilkinson JL, Lozsadi K, Macartney FJ, Anderson RH. Morphology and classification of atrioventricular defects. Br Heart $\mathrm{J}$ 1979;42:621-32.

13 Piccoli GP, Wilkinson JL, Macartney FJ, Gerlis LM, Anderson RH. Morphology and classification of complete atrioventricular defects. $\mathrm{Br}$ Heart $\mathrm{J}$ 1979;42:633-9.

14 Smallhorn JF, Tommasini G, Anderson RH, Macartney FJ. Assessment of atrioventricular septal defects by two dimensional echocardiography. $\mathrm{Br}$ Heart J 1982;47:109-21.

15 Gussenhoven EJ, Becker AE. Congenital heart disease. Morphologic echocardiographic correlations. Amsterdam: Churchill Livingstone, 1983:102-17.

16 Hagler DJ. Atrioventricular canal defects. Philadelphia: WB Saunders, 1976:87-109.

17 Bass JL, Bessurger FB, Lawrence C. Echocardiographic differentiation of partial and complete atrioventricular canal. Circulation 1978;57:1144-50.

18 Mortera C. Echocardiography of atrioventricular canal malformations. In: Lundström NR, ed. Pediatric echocardiography-cross-sectional, M-mode, and Doppler. Amsterdam: Elsevier/North Holland, 1980: 187-96.

19 Seward JB, Tajik AJ, Hagler DJ, Edwards WD. Internal cardiac crux: two dimensional echocardiography of normal and congenitally abnormal hearts. Ultrasound Med Biol 1984;10:735-45.

20 Bharati S, Lev M, McAllister HA, Kirklin JW. Surgical anatomy of the atrioventricular valve in the intermediate type of common atrioventricular orifice. $J$ Thorac Cardiovasc Surg 1980;79:884-9.

21 Sutherland GR, Van Mill GJ, Anderson RH, Hunter S. Subxiphoid echocardiography - a new approach to the diagnosis and differentiation of atrioventricular defects. Eur Heart $J$ 1980;1:45-55.

22 Medina Fernandez A, Bethencourt Gonzalez A, Macaya Miguel C, Tynan M, Anderson RH. Subxiphoid M-mode echocardiography in atrioventricular defects. Pediatr Cardiol 1982;3:119-25.

23 Tajik AJ, Seward JB, Hagler DJ, Mair DD, Lie JT. Two-dimensional realtime ultrasonic imaging of the heart and great vessels. Technique, image, orientation, structure identification and validation. Mayo Clin Proc 1978;53:271-303. 